\title{
A INFLUÊNCIA DAS COMUNICAÇÕES NA CARGA DE TRABALHO DO CONTROLADOR DE TRÁFEGO AÉREO
}

\section{THE INFLUENCE OF COMMUNICATIONS IN THE WORKLOAD OF AIR TRAFFIC CONTROLLERS}

\author{
Arlete Ana Motter ${ }^{19}$ \\ Leila Amaral Gontijo ${ }^{20}$
}

\section{Resumo}

Os controladores, em sua rotina laboral, muitas vezes, trabalham sob elevada carga de trabalho e, certamente devem cumprir elevado nível de segurança. As comunicações, via radiofonia, tem sido um dos principais problemas técnicos, no complexo sistema de controle de tráfego aéreo brasileiro. Objetivo: avaliar a influência das comunicações na carga de trabalho do controlador de tráfego aéreo. Participaram 35 militares do CINDACTA II (Segundo Centro Integrado de Defesa Aérea e Controle de Tráfego Aéreo) de Curitiba, (80\% do sexo masculino e $20 \%$ do sexo feminino). Foi aprovado pelo CEP da UTP e fez parte da tese de doutorado, defendida em 2007, no Programa de Pós Graduação em Engenharia de Produção da UFSC. Nos resultados o item mais desgastante foi freqüências com interferências ou falhas de comunicações, problema que tem aumentado nos últimos anos devido à "radio pirata" e telefonia celular, associado à precariedade de equipamentos de comunicação.

Palavras-chave: controlador de tráfego aéreo; comunicações; carga de trabalho.

\footnotetext{
${ }^{19}$ Doutora, Professora Adjunto I da Universidade Federal do Paraná - Litoral. E-mail: arlete.motter@uol.com.br

${ }^{20}$ Doutora, Programa de Pós Graduação em Engenharia de Produção da Universidade Federal de Santa Catarina.
} 


\section{Introdução}

Há diferentes atores envolvidos no cenário de complexidade do controle de tráfego aéreo. A segurança na aviação depende de decisões que envolvem habilidades técnicas, humanas e também a percepção de todo horizonte que está a sua volta. Um desses atores é o controlador de tráfego aéreo, o qual, além de decidir quem tem prioridade de pouso e de decolagem, tem de analisar uma gama de informações de profunda complexidade (BISPO e FERRUCCIO, 2001).

Inicialmente, eles eram formados pela Escola Técnica de Aviação de São Paulo e pela Escola de Especialistas da Aeronáutica, no Rio de Janeiro, mais tarde transferida para a cidade de Guaratinguetá (São Paulo). Atualmente, os controladores são formados pela Escola de Especialistas da Aeronáutica de Guaratinguetá (militares) e pelo Instituto de Proteção ao Vôo, em São José dos Campos, São Paulo (controladores civis e formação avançada para controladores militares e civis).

O controlador de tráfego aéreo é o principal protagonista de todos os tráfegos aéreos correntes (aeronaves prontas para pouso ou decolagem) e pendentes (aeronaves que estão em espera para pouso ou decolagem); e, como tal, também responsável por uma série de informações referentes a eles. Para a realização de sua função, executa uma série de tarefas, que totalizaram 83 tarefas diferentes, no estudo realizado em 1987, no CINDACTA I, em Brasília (PASQUALI e LAGO, 1987).

Devido ao elevado nível de tarefas cognitivas, o trabalho do controlador de tráfego aéreo demanda grande carga mental e emocional, pois é ele quem toma as decisões finais, o que, quase sempre, dever ser feito em tempo muito restrito. É uma função que exige agilidade intelectual, velocidade de raciocínio, boa resistência ao estresse e capacidade de adaptação. Por isso ele é considerado, na Europa, Artesanato Intelectual (MOREIRA e VIDAL, 1999).

Além disso, realiza uma tarefa que exige alta atenção prolongada, relacionada com elevada responsabilidade (PASQUALI e LAGO, 1987; MOREIRA e VIDAL, 1999). Assim como Itani (1997, p.198) relata em seu estudo desenvolvido com metroviários de São Paulo, o ritmo de trabalho para os controladores não é sempre o mesmo, mas é sempre um tempo de espera: "Quando está atento, o tempo é o da espera, alongado pela incerteza e pela expectativa da espera [...] O tempo é tecido pela angústia da possibilidade de perder a atenção". Assim, as freqüentes mudanças de ritmo de trabalho que se sucedem ao longo da mesma jornada de 
trabalho, segundo essa autora, são altamente estressantes e consideradas nocivas para a saúde dos operadores.

O controlador é um dos muitos agentes de segurança. Sua função é garantir a segurança para todos os que estão a bordo da aeronave, passageiros e tripulação, e também de quem está em terra (BISPO e FERRUCCIO, 2001). Por isso, Rebello (1997, p.18) afirma que:

\footnotetext{
Os controladores de tráfego aéreo constituem um grupo especial de trabalhadores, uma vez que exercem sua atividade de alta responsabilidade em um ambiente físico adverso, onde existem variações ambientais e cronobiológicas devido ao ambiente de trabalho confinado e à jornada de trabalho em turnos alternados. Eles são o "elo de ligação da aeronave (mais tripulação, passageiros e carga) entre a terra e o ar".
}

Segundo Gras et al. (apud PEREIRA, 2001), a vulnerabilidade do trabalho do controlador de vôo está relacionada ao confronto entre o trabalho automatizado (controle de tráfego por radar e computadores) e o aspecto artesanal e sensorial (interpretação de informações visuais e auditivas). Há uso dos sentidos físicos e, ao mesmo tempo, da memória.

$\mathrm{Na}$ concepção do trabalho do controlador de tráfego aéreo, as comunicações utilizadas pelos operadores são de vital importância, conforme destaca Rebello (1997, p.19): "O trabalho do controlador de vôo apresenta uma linguagem operacional particular. A linguagem utilizada durante o trabalho não é uma simples linguagem de comando, pois é um campo em que são utilizados vários símbolos de muitos significados e formas de expressão".

$\mathrm{Na}$ comunicação verbal, via radiotelefonia, apesar de existir uma fraseologia mundialmente conhecida, podem surgir alguns embaraços, quando não se domina o idioma inglês, que é obrigatório para o trabalho dos controladores de tráfego aéreo (e também para os pilotos), ou então, ruídos, chiados, interrupções no sistema de comunicações. Se houver demora na compreensão das mensagens, há risco para a segurança nas operações (MOTTER, 2007).

Os controladores usam sistemas computadorizados complexos, interconectados com seu país e com os outros. Em alguns órgãos de controle (Madri, Espanha e Copenhague, Suíça), os controladores têm ainda um link de vídeo para saber como os outros controladores mais distantes estão organizando os tráfegos e como eles estão seqüenciando os vôos na chegada (MERTZ, 2003).

A radiotelefonia nas condições modernas de controle de tráfego aéreo tem se configurado com dificuldade, devido à possibilidade de ruídos nas transmissões. Segundo 
Rebello (1997) e Bispo e Ferruccio (2001), não adianta haver um sistema de captação de radares e de computação totalmente automatizado e moderno, se as radiofreqüências não funcionarem adequadamente para o controlador poder transmitir e receber informações orientadas aos pilotos durante os procedimentos aéreos.

Podem se instalar nesses profissionais reações de estresse, demonstradas por meio de questionários e pela dosagem da excreção de catecolaminas. Num estudo com controladores de Zurique, observou-se que, nas primeiras quatro a sete horas de trabalho, toma lugar uma sensível diminuição da capacidade subjetiva de prontidão da produção e as realizações psicofisiológicas e, após a sétima hora, ocorre forte aumento da fadiga tanto no campo dos indicadores objetivos quanto dos subjetivos (GRANDJEAN, 2005). Estão expostos a eventos estressores ligados a atividade de trabalho como urgência de tempo, responsabilidade excessiva, redução da qualidade do sono (MENDES e CRUZ, 2004).

Para Athènes et al. (2002) o fator tempo e a incerteza, ambas ligadas à carga de trabalho, tem relação com o estado emocional dos controladores, principalmente durante situações de alta carga de tráfego. Lamoureux (1999) observou que as comunicações são um indicador de carga de trabalho e estão relacionadas diretamente a outros fatores, em particular, ao número de aeronaves sob controle, às coordenações entre setores, às solicitações não usuais dos pilotos e às emergências.

O estudo realizado no ACC de Curitiba, por Sauki, Filho e Brito (2003), revelou que muitos controladores sofrem de diferentes doenças causadas pelo trabalho, como: tendinite, dores nas articulações, danos na visão, problemas psicológicos, dores de cabeça, depressão, perda de concentração, fadiga e estresse.

Mais especificamente no ACC de Curitiba, existem 19 atribuições operacionais que competem ao controlador de tráfego aéreo de setor, porém, quando operam como assistente de controlador de setor, podem-se encontrar mais 15 atribuições prescritas aos trabalhadores (BRASIL, 2005).

Sauki, Filho e Brito (2003, p.58) citam uma série de requisitos necessários aos operadores de tráfego aéreo:

a) ter excelente raciocínio espacial;

b) ter boa saúde física e mental;

c) ter boa dicção;

d) saber emitir as instruções aos pilotos;

e) saber registrar de forma codificada as instruções emitidas aos pilotos;

f) conhecer profundamente as regras de tráfego aéreo; 
g) consultar e interpretar publicações aeronáuticas, documentos, mapas e cartas aéreas;

h) conhecer as rotas aéreas em geral;

i) saber a localização geográfica dos aeródromos da região onde os sistemas estão inseridos;

j) saber as influências dos fenômenos meteorológicos (ventos, formações de gelo, nuvens, turbulências, trovoadas, pressões etc.);

k) saber operar o sistema de tratamento de planos de vôos; e

l) saber principalmente identificar as aeronaves e interpretar as imagens fornecidas pelo radar.

A psicóloga Maria da Conceição Pereira (2001) descreve os aspectos psíquicos na relação pilotos controladores, citando aspectos que devem estar presentes nos perfis psicológicos ocupacionais de controladores: ser seguro de si, decidido, realista, estável emocionalmente, perseverante, teórico e orientador consciencioso, questionador e exigente consigo mesmo. No mesmo estudo, a autora aborda os aspectos que envolvem os processos cognitivos de pilotos e controladores: atenção, concentração, percepção sensorial, raciocínio espaço temporal, memória visual e auditiva (de longo e de curto prazo), raciocínio lógico e fluência verbal (domínio de línguas estrangeiras).

\section{Metodologia}

A pesquisa caracteriza-se como exploratória e descritiva, emprega o método estudo de casos e a metodologia da Análise Ergonômica do Trabalho (Guérin, et al., 2001).

O estudo foi desenvolvido no Centro de Controle de Área de Curitiba (ACC-CW), no Segundo Centro Integrado de Defesa Aérea e Controle de Tráfego Aéreo (CINDACTA II), o qual pertence ao Ministério da Defesa - Comando da Aeronáutica. O ACC de Curitiba trata cerca de 2.000 planos de vôos diários, que inclui o tráfego aéreo de toda região sul do país.

A amostra foi composta por 35 controladores de tráfego aéreo, militares, da Força Aérea Brasileira (FAB), de ambos os sexos ( $80 \%$ homens e $20 \%$ mulheres), cuja idade média é de 26,8 anos.

A população de referência deste estudo foi acompanhada no período matutino, vespertino ou noturno, durante a semana ou finais de semana e feriados. Acompanhou-se operadores dos 7 setores do ACC de Curitiba: setor de chegada de São Paulo, setor de Porto Alegre, setor de Florianópolis, 2 setores de saída de São Paulo, setor de Foz do Iguaçu e 2 setores de Campo Grande. Nas transcrições das verbalizações, os controladores foram 
identificados por números (de 1 ao 35), com o intuito de manter o sigilo quanto a identificação dos entrevistados.

O estudo representa um recorte da tese de doutorado defendida em 2007, no Programa de Pós-Graduação em Engenharia de Produção, da Universidade Federal de Santa Catarina (MOTTER, 2007).

Buscou-se respeitar os princípios éticos de acordo com a Resolução 196/96 do Conselho Nacional de Saúde assim, o projeto foi submetido e aprovado pelo Comitê de Ética em Pesquisa da Universidade Tuiuti do Paraná, Of. CEP- UTP n 085/2006, posteriormente foi iniciada a coleta de dados.

Os principais métodos e técnicas de coleta de dados foram: análise documental, entrevistas informais e semi-estruturadas, observações gerais e sistematizadas e registros de verbalizações.

\section{Resultados e Discussão}

A comunicação é elemento essencial no processo de interação controlador-pilotos. Os controladores afirmam que operar sem radar é possível, mas operar sem freqüência de comunicações é impossível, por ser essa uma condição mínima necessária para garantir a segurança na aviação. Dessa forma, o item mais apontado como desgastante no controle de tráfego aéreo foi sem dúvida a questão de freqüências com interferências ou falhas de comunicações, problema que tem aumentado nos últimos anos, devido a "rádio pirata" e telefonia celular, associado à precariedade de equipamentos de comunicação.

O problema de comunicações resulta em dificuldade perceptiva auditiva para operadores e para pilotos. Wisner (1987) aponta as dificuldades perceptivas como um dos fatores que aumentam a carga de trabalho. Quando questionados sobre como se sentem quando há problemas de freqüências para comunicações revelou que $61,8 \%$ dos operadores admitem se sentir totalmente desconfortáveis e $38,2 \%$ se sentem desconfortáveis, o que resulta em 100\% deles responderem negativamente quanto a esse tipo de dificuldade técnica para o trabalho, situação tão comum no cotidiano dos sujeitos da pesquisa, que se tornou motivo de ironia: "O negócio é rir para não chorar".

Ao contrário, quando questionados sobre como se sentem operando com freqüência de comunicação em boas condições (condição tão incomum que provocou risos em vários 
operadores), $60 \%$ relataram sentir-se totalmente confortáveis e $40 \%$ dos operadores relataram sentir-se confortáveis. Nesse caso, não houve resposta "desconfortável" ou "totalmente desconfortável". As expressões de alguns operadores - "O dia em que isso acontecer vai ser um sonho"; "Freqüências em boas condições? Isso ainda não passou por aqui"; "É coisa rara" - ilustram o quanto trabalhar em condições adequadas de comunicações é raro no controle de tráfego aéreo deste estudo. Tanto é assim que alguns operadores já sabem como resolver o problema, e não aguardam o técnico de comunicações para resolvê-lo.

As falas a seguir demonstram as estratégias operatórias adotadas pelos controladores, com relação aos problemas de comunicações, e ilustram a gravidade da situação, que representa um risco potencial de acidente.

Operador 15: Se você tem problema de freqüências você começa a restringir o número de aeronaves no setor ou até mesmo fechar o setor. Se você não fala com o avião e tem dois aviões proa a proa, você não tem como separar, entendeu? Agora, se você não está vendo e tem freqüência, pela ficha de progressão, pelos [tempos] estimados, você sabe que os dois aviões estão proa a proa, mas sem a freqüência, é impossível.

Operador 16: Se não tiver freqüência, o que a gente faz? Se tiver radar, dá a proa para decolagem ou, dependendo, se for muito grave, na verdade, a gente informa o problema ao supervisor, que toma todas as providencias. O esquerdinha aqui vai fazer isso, oh: "Não vai voar ninguém no mesmo nível ou em nível que possa se conflitar", porque você sabe que, na hora em que você precisar, pode não funcionar, ou, se for uma situação de muito caos de freqüência, todo mundo no chão. Ninguém decola. E aí o supervisor toma essa atitude também. Por isso ele fala: "Viro e chamo o supervisor", porque seria isso, o supervisor que vai passar o problema para ele. Ele vai falar "não vai fazer isso". Ele sabe que não tem mais o que fazer.

O discurso dos operadores entrevistados denota que esse tipo de perturbação exige atenção, concentração e agilidade dos controladores, e torna-os bastante tensos.

Operador 16: [...] você tem que repetir três, quatro vezes, porque não chega bem para ele, entendeu? E às vezes você vai transmitir e aí acontece o quê? É um cuidado que a gente tem que tomar daquele cotejamento. Você vai transmitir, de repente, transmite uma rádio junto com ele lá. Ele entende só parte da mensagem que você falou, só que você não está ouvindo isso, você acredita que ele ouviu inteira. Aí ele fala "ciente". 
Operador 17: A tua expectativa é que ele entenda e faça o que tu estás falando. Principalmente numa situação de separação de rotas conflitantes. Tu queres que ele entenda e curve logo. Se é situação de seqüenciamento e ele não entender, tu ainda vais poder corrigir, mas se é uma situação de rota conflitante ou uma rota perigosa, tu tens que tirar ele dali ou... [interrompido pelo tráfego].

O operador 17 explica a dificuldade de operar quando há problemas de fonia, que pode ser uma dificuldade do operador em relação ao piloto, do piloto em relação ao controlador ou de ambos simultaneamente. O ápice da tensão vivida nesse tipo de situação é quando existe risco iminente de incidente ou acidente. Esse operador levanta a questão da divisão do trabalho, que ocorre pelo número de tráfego, e não pelo contexto do momento. Interessante também é observar a percepção do próprio operador em relação a sua carga de trabalho, que considera principalmente mental:

Operador 17: Eu acho que a parada que mais pega é quando tu planejas uma coisa e a coisa não acontece, ou então, como tu estavas falando, o problema de freqüência, que eu acho que é o nosso maior problema. É quando tu estás falando com o piloto e o piloto não está te ouvindo. Aí tu tens que repetir, tens que repetir, e às vezes é um negócio de imediato, que tu precisas de uma reação do piloto imediata, e ele não te ouve, ele te questiona, porque ele não entendeu direito. Esse acho que é o ponto cume do estresse de quem trabalha. Geralmente isso acontece, não quando você tem dois ou três tráfegos, assim, sabe? Quando tu tens muito tráfego, tu estás trabalhando, como agora a gente tem pouco, tu podes ver que a gente tem bastante trabalho. Não pára de atender telefone. Eu estou falando toda hora, e não tem muito tráfego. Então, tu imaginas com o máximo de tráfego que eles delimitam por setor. E tu falando e o piloto não te entendendo. Então eu acho que essa é a parte que mais, assim, te desgasta, mentalmente falando. Fisicamente, eu não tenho trabalho nenhum, fico só apertando botão. Agora com relação ao desgaste mental, assim, estresse maior é nesse tipo de situação, de tráfego e a freqüência com problema.

Operador 19: Você chama e a aeronave não responde. Você tem que ficar mais atento, restringir nível.

O operador 20 deixa transparecer em seu discurso que o trabalho no controle de tráfego aéreo não é impessoal, existem afetos, ou seja, há exigência psíquica para a realização 
do trabalho. É o que pode se verificar quando ele classifica os problemas de freqüências em quatro áreas:

1. Queda na transmissão ou recepção ou ambas as situações. Então, fica sem comunicação parcial ou total. Esse tipo de problema "preocupa". [...] Você fica sem ação, você se sente impotente, você quer passar uma informação e não consegue. Você não tem o conhecimento técnico para resolver o problema. Você fica muito preocupado. Apesar de a imprensa dizer que a gente não se preocupa com as pessoas que estão voando, a gente fica muito preocupado. A gente não fica insensível à aeronave que caiu.

2. Comunicação entrecortada: quando a mensagem se torna inelegível.

3. Telefonia celular/rádio pirata, rádio FM, piloto ou operador ou os dois ouvem música, conversas de rádio ou telefone.

4. Chiado. Ocorre principalmente quando há tempestade.

O operador explica que os itens 2, 3 e 4 incomodam, porém, o item que realmente preocupa é o numero 1. Quando questionado sobre como costuma lidar com esse tipo de dificuldade, diz que, se a situação do tráfego não exigir ação imediata, aguarda o pessoal técnico para resolver o problema. Se o tráfego exigir ação imediata, entra na freqüência de emergência (1.5Mhz), em que todas as aeronaves estão ligadas. Em segundo lugar, iria para outro setor, onde a freqüência estivesse normal e solicitaria que outra aeronave transmitisse as informações (o que é chamado de "ponte").

Ficam nítidos a falta de confiança nos equipamentos de trabalho e o desgaste que isso causa, segundo a fala do operador 16, o qual utiliza o termo antecipação como sinônimo de planejamento:

O pessoal fala: "Ah, a profissão é muito estressante". É estressante se você não tiver os meios para poder trabalhar. Se você tiver uma estrutura para trabalhar, isso não se torna estressante. Por quê? Se você soubesse que você poderia contar sempre com as freqüências, não precisaria ficar se estressando na decolagem. Tem que tomar certas restrições na decolagem, que ele [o piloto] vai te chamar, você vai tomar as providências. Lógico, a antecipação faz totalmente parte e é essencial para o trabalho, situação tipo de tomada de decisão e resolução de conflitos. 
A troca de informações entre o controlador e uma aeronave é compartilhada pelos demais pilotos de aeronaves que estão utilizando a mesma freqüência para comunicação. Isso facilita o que o controlador chama de ponte.

No trabalho real, acompanhou-se um operador com assistente e instrutor no setor de Mato Grosso do Sul e São Paulo operarem com deficiência de transmissão (operador e piloto não conseguiam ouvir a mensagem), tinham de repetir várias vezes a fraseologia. Fazia ecofonia quando o operador falava com a aeronave, então, a fraseologia era repetida lentamente. Após falar ao microfone, com uma das aeronaves, o operador ironizou a situação dizendo: "...e do raio que o parta".

Em entrevista, a operadora 26, quando questionada sobre como se sente quando há falha na freqüência de comunicação, fala que sente muita raiva, mas, como esse sentimento não resolve nada, então, não tem o que fazer, a não ser aguardar o restabelecimento do sistema. Em sua opinião, existem coisas bem mais importantes para o operador fazer do que ficar "resetando", porque, segundo ela, a primeira pergunta que o supervisor faz quando é avisado de que a qualidade da comunicação não está boa é: Você já tentou "resetar"? Ela se sente desqualificada em ter de ficar "apertando botão para tentar comunicação", uma vez que sua formação técnica não é para isso.

Para garantir o desempenho operacional, o controlador desenvolve algumas estratégias, tais como: chamar o pessoal técnico de manutenção; e, enquanto aguarda a manutenção, ele próprio tenta restabelecer o sistema ("resetar"); suspender decolagens ou restringir níveis de vôo; repetir mensagens (cotejamento); trabalhar em equipe (cooperação); fazer comunicação por meio de outra aeronave (ponte); fornecer informação prévia às aeronaves quanto à freqüência de comunicação alternativa em caso de falha naquela que está sendo utilizada: "Em caso de falha de comunicações, faça tal e tal coisa", ao que chamam de "pagar alternativa".

\section{Conclusões}

Compreende-se que os controladores constroem uma série de estratégias operatórias para fazer frente às solicitações de intensidade e ritmo de trabalho, as quais servem, também, para lidar com a imprevisibilidade e variabilidade (de informações, de procedimentos, de equipamentos e de atribuições) presentes em seu cotidiano. 
Entende-se que as estratégias operatórias são construídas pelo controlador de tráfego aéreo, a fim de reduzir sua carga de trabalho, principalmente a carga de trabalho mental. Esse mecanismo faz-se necessário para manter o equilíbrio psíquico dos operadores, e garantir a continuidade de prestação de serviços no transporte aéreo e na segurança da aviação.

Como proposta de intervenção, sugere-se a atualização do sistema de comunicações e também do posto de trabalho (console), pois o modelo atual, da década de 80, é considerado desatualizado. Nesse sentido, novas exigências cognitivas serão impostas aos controladores, e deve-se prever período de adaptação e treinamento.

\section{Referências}

ATHÈNES, S.; AVERTY, P.; PUECHMOREL, S.; DElAHAYE, D.; COLLET, C. ATC Complexity and Controller workload: trying to bridge the gap. HCI-Aero, 2002.

BISPO, J. C.; FERRUCCIO, M. A. et al. Prevenção de catástrofes na aviação? Anais ABERGO, Gramado, 2001.

BRASIL. Ministério da Defesa. Portaria do CINDACTA II. Modelo Operacional do Centro de Controle de Área de Curitiba, PR nº 7/CMDO, de 02 de março de 2005.

GRANDJEAN, E. Manual de ergonomia. Adaptando o trabalho ao homem. Porto Alegre, 2005.

GUÉRIN, F.; LAVILlE, A.; DANIELlOU, F.; DURAFFOURG, J.; KERGUELLEN, A. Compreender o trabalho para transformá-lo: a prática da ergonomia. São Paulo: Edgard Blücher, 2001.

ITANI, A. Subterrâneos do trabalho: imaginário tecnológico no cotidiano. São Paulo: Hucitec, 1997.

LAMOUREUX, T. The influence of aircraft proximity data on subjective mental workload of controllers in the air traffic control task. Ergonomics, v. 42, n. 11, p. 1482-1491, 1999.

MENDES, A. M. e CRUZ, R. M. Trabalho e saúde no contexto organizacional: vicissitudes teóricas. In: TAMAYO, A. e colaboradores. Cultura e saúde nas organizações. Porto Alegre: Artemed, 2004.

MERTZ, C. Peripheral awareness offered by interaction techniques in air traffic control interfaces. Proposed contribution to the "CHI 2003 WORKSHOP: PROVIDING ELEGANT PERIPHERAL AWARENESS”. Toulouse, France, 2003. 
MOREIRA, S. B. e VIDAL, M. C. Relatórios de pesquisas ergonômicas realizadas no controle de tráfego aéreo do Rio de Janeiro (APP/RJ), 1999.

MOTTER, A.A. Análise da Carga de Trabalho em Sistemas Complexos: gestão da variabilidade e imprevisibilidade nas atividades do controlador de tráfego aéreo. 2007. 218f. Tese (Doutorado em Engenharia de Produção) Universidade Federal de Santa Catarina, Florianopolis.

PASQUALI, L.; LAGO, L. J. A. Controlador de tráfego aéreo - análise de cargo. Brasília, 1987.

PEREIRA, M. C. Aspectos psicológicos no controle de tráfego aéreo e o controlador de tráfego aéreo: elaborações de uma prática em construção. In: PEREIRA, Maria da Conceição e RIBEIRO, Selma Leal de O. (Orgs.). Os vôos da psicologia no Brasil: estudos e práticas na aviação. Rio de Janeiro: DAC: NuICAF, 2001.

REBELLO, L. H. B. O controle de tráfego aéreo numa perspectiva contemporânea em Engenharia de Produção. 1997. Tese (Doutorado em Ciências em Engenharia de Produção) - Programa de Pós-graduação em Engenharia, UFRJ, Rio de Janeiro.

SAUKI, M. A.; FILHO, P. H. W.; BRITO, V. M. Estudo de adaptação ergonômica em consoles de tráfego aéreo. Trabalho de conclusão do Curso de Tecnólogo em Mecânica, Gestão em Manufatura. Centro Federal de Educação Tecnológica do Paraná, Curitiba, 2003.

WISNER, A. Por dentro do trabalho. Ergonomia: método e técnica. São Paulo: FTD: Oboré, 1987. 